\title{
An Open-Label Pilot Study of Acetylcholinesterase Inhibitors to Promote Functional Recovery in Elderly Cognitively Impaired Stroke Patients
}

\author{
Ellen M. Whyte ${ }^{a} \quad$ Eric J. Lenze ${ }^{g} \quad$ Meryl Butters $^{a} \quad$ Elizabeth Skidmore $^{b}$ \\ Kris Koenig ${ }^{a}$ Mary Amanda Dew ${ }^{a, d, e}$ Louis Penrod $^{c}$ Benoit H. Mulsant ${ }^{a}$ \\ Bruce G. Pollock ${ }^{a}$ Leonard Cabacungan ${ }^{c}$ Charles F. Reynolds, III ${ }^{a}$ f \\ Michael C. Munin ${ }^{\mathrm{C}}$ \\ Departments of a Psychiatry, ${ }^{\mathrm{b}}$ Occupational Therapy, ${ }^{\mathrm{C} P h y s i c a l}$ Medicine and Rehabilitation, ${ }^{\mathrm{d}}$ Psychology, \\ ${ }^{e}$ Epidemiology, and ${ }^{\mathrm{f} N e u r o l o g y, ~ U n i v e r s i t y ~ o f ~ P i t t s b u r g h ~ S c h o o l ~ o f ~ M e d i c i n e, ~ P i t t s b u r g h, ~ P a ., ~ a n d ~}$ \\ ${ }^{9}$ Department of Psychiatry, Washington University School of Medicine, St. Louis, Mo., USA
}

\section{Key Words \\ Cerebrovascular accident • Cholinesterase inhibitors • \\ Rehabilitation, elderly $\cdot$ Cognition, stroke $\cdot$ Apathy, stroke}

\begin{abstract}
Background: Impairments in cognition and motivation are common after stroke and predict poor functional recovery. Pharmacological agents that enhance cognition and/or diminish apathy may, when combined with traditional rehabilitative efforts, improve functional recovery. We investigated the feasibility of using acetylcholinesterase inhibitors in older patients with acute post-stroke cognitive impairment and examined their effects on functional recovery. Methods: This 12-week open-label study prospectively treated ischemic stroke survivors aged $\geq 60$ years who were undergoing inpatient rehabilitation and who had cognitive impairment in one or more domains (memory, attention or executive function). Participants received galantamine (maximum dose $24 \mathrm{mg} /$ day) or donepezil (maximum dose $10 \mathrm{mg} /$ day). Physical function was assessed using the Functional Independence Measure-motor subscale (FIM-motor); participants' functional gains were compared to those of a matched historical comparator group. Changes in cognition and apathy were also assessed. Since donepezil and galantamine
\end{abstract}

\section{KARGER}

Fax +41613061234

E-Mail karger@karger.ch

www.karger.com

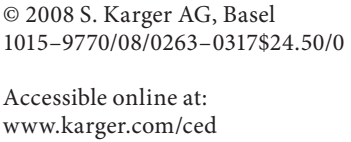

have different pharmacologic profiles, they were examined separately. Results: Forty participants started study medication; 14 participants terminated prematurely. Donepeziltreated participants experienced a 14-point greater improvement in the FIM-motor score compared to either galantamine-treated participants or the historical comparator group (repeated measures mixed model, group $\times$ time interaction $p<0.0001$ ). Change in apathy, but not in cognition, was also associated with change in the FIM-motor score. Conclusions: In this open-label study, participants receiving donepezil had better functional recovery than participants receiving galantamine or the historical comparators. This improvement may reflect efficacy at the starting dose for donepezil but not galantamine. A randomized trial is in progress.

Copyright $\odot 2008$ S. Karger AG, Basel

Data were presented, in part, at the 2 nd annual VAS-COG meeting in Florence, Italy, in June 2005.

E.M.W. has received drug supplies from Pfizer for another study. E.J.L. has received grant funding from Forest, Novartis, Pfizer and Janssen. B.H.M. is the principal investigator for a grant from Janssen and has received drug supplies from Pfizer, has been a speaker for Pfizer and Janssen, owns stock in Pfizer, and sits on advisory boards for both Janssen and Pfizer. B.G.P. has received research funds from Janssen and is a consultant for Janssen. C.F.R. has received research funds from GlaxoSmithKline, Pfizer, Forest and Lilly.

Eric J. Lenze, MD

Department of Psychiatry, Washington University School of Medicine

660 S. Euclid, Box 8134

St. Louis, MO 63108 (USA)

Tel. +1 314362 1671, Fax +1 314362 7017, E-Mail lenzee@wustl.edu 


\section{Introduction}

Impairments in cognition [1] and motivation [2] are common after stroke and predict poor functional recovery [3-5]. We propose that pharmacological agents that enhance cognition and/or diminish apathy may, when combined with traditional rehabilitative efforts, lead to improved functional recovery. Acetylcholinesterase inhibitors (AchEi) are candidate agents based on studies demonstrating that AchEi: (1) have cognitive benefit in vascular dementia, Alzheimer's disease with comorbid cerebrovascular disease [6-8], and delirium concurrent with vascular dementia [9], and (2) can work acutely, improving attention within hours of the first oral dose [10]. AchEi also have antiapathy effects in dementia [11], consistent with the evidence that apathy is the result of decreased cholinergic innervation [12].

For this pilot study, we hypothesized that the use of donepezil or galantamine in patients with acute poststroke cognitive impairment would be feasible and associated with superior rehabilitation outcomes compared to a historical group of stroke patients. We also explored changes in cognition and apathy and compared the two AchEi, given their different pharmacologic profiles.

\section{Methods}

Participants were recruited from three inpatient rehabilitation units at the University of Pittsburgh Medical Center. Written informed consent was obtained in accordance with the University Institutional Review Board's procedures. Inclusion criteria were: aged $\geq 60$ years; ischemic stroke within the last 30 days, and cognitive impairment (either of new onset or markedly worse since stroke, as reported by the subject and their family). Participants were included if they scored at least 1 standard deviation below age-matched norms on the Hopkins Verbal Learning Test for memory [13], Digit Span summary score from the Wechsler Adult Intelligence Test for attention [14] or Executive Interview [15] for executive function. Exclusion criteria were: previous diagnosis of Alzheimer's disease based on a clinical evaluation by the investigators (E.M.W. and E.J.L.) that included reports from the patient, family and primary care provider as needed; prestroke or current treatment with an AchEi or memantine; aphasia or behavioral impairments prohibiting study assessments; current major depressive episode, psychosis or mania, and substance/alcohol abuse within the last 3 months.

Participants were assigned to donepezil $(n=20)$ or galantamine $(\mathrm{n}=20)$ in an order determined by study drug availability. Galantamine was dosed at $4 \mathrm{mg}$ twice a day (b.i.d.) for 4 weeks, then $8 \mathrm{mg}$ b.i.d. for 4 weeks, and then $12 \mathrm{mg}$ b.i.d. for 4 weeks. Donepezil was dosed at $5 \mathrm{mg} /$ day for 6 weeks and then at $10 \mathrm{mg} /$ day for 6 weeks. Doses were decreased or titration delayed if side effects emerged.
Participants were assessed with the Functional Independence Measure (FIM $\left.{ }^{\mathrm{TM}}\right)$ [16] and the Apathy Evaluation Scale [17] at baseline, week 2 (or discharge from inpatient rehabilitation) and week 12. A prestroke FIM, reflecting the participant's disability level prior to the index stroke, was obtained. The FIM rater was blinded to study medication assignment. Only the 13 motor items of the FIM (FIM-motor) [18] were used in statistical analyses as other, more sensitive, instruments were used to assess mood and cognition. The Hopkins Verbal Learning Test, Digit Span, and Executive Interview were repeated at 12 weeks by a rater who was not blinded to study medication assignment. A side effect checklist was used to score the 11 most common AchEi side effects from 0 (absent) to 3 (severe) for each symptom. Brain-imaging studies conducted for routine clinical management were reviewed for stroke location.

A historical comparison group was derived via chart review of all elderly ischemic stroke survivors admitted to the UPMC Rehabilitation Hospital (the main recruitment site for this study) between January 29, 1996, and December 22, 1999. The historical comparator group $(\mathrm{n}=110)$ was created by group-matching the historical patients to study participants, sequentially, by FIM-motor score at admission, age and length of inpatient rehabilitation.

\section{Data Analysis}

The donepezil and galantamine groups were examined separately due to the drugs' different pharmacologic profiles. The baseline demographic and clinical characteristics for the 3 groups (galantamine, donepezil and historical comparator) were compared using analysis of variance (ANOVA) for continuous variables and using Fisher's exact test for categorical data. Appropriate transformations were used for nonnormally distributed continuous variables.

Side effects, cognition, apathy and FIM-motor scores for the 2 AchEi groups were analyzed using a repeated measures mixed model to examine group, time and group $\times$ time interactions. An unstructured variance-covariance matrix was used. Due to the different variances in FIM-motor scores, the residual matrix was allowed to have different variances for each group in the FIM-motor model [19]. Separate mixed models for the FIM-motor scores were also run, controlling for cognition and apathy individually. The mixed models for FIM-motor scores were repeated with the 3 groups using the same assumptions on the variance-covariance matrix.

\section{Results}

From February 25, 2003, to January 27, 2005, 314 elderly ischemic stroke survivors were admitted for inpatient rehabilitation. Sixty-seven patients consented to this study, 20 were subsequently excluded in accordance with the protocol, and 7 refused to start study medication. Thus, 40 participants started study medication.

\section{Study Dropouts}

Fourteen participants $(7$ receiving donepezil, 7 on galantamine) dropped out prior to week 12. At baseline, 
Table 1. Baseline demographic and clinical characteristics of study completers

\begin{tabular}{|c|c|c|c|c|}
\hline & $\begin{array}{l}\text { Donepezil } \\
(\mathrm{n}=13)\end{array}$ & $\begin{array}{l}\text { Galantamine } \\
(\mathrm{n}=13)\end{array}$ & $\begin{array}{l}\text { Historical } \\
\text { comparator } \\
(\mathrm{n}=98)\end{array}$ & $\begin{array}{l}\text { Test statistic, d.f., } \\
\text { p value } \\
\text { (Tukey post hoc) }\end{array}$ \\
\hline Age, years & $69.1(6.4 ; 66)$ & $69.9(7.5 ; 67)$ & $72.2(5.8 ; 72)$ & $\begin{array}{l}F=2.21 ; \text { d.f. }=2,121 \\
p=0.11\end{array}$ \\
\hline Male, \% & $61.5(\mathrm{n}=8)$ & $76.9(\mathrm{n}=10)$ & $48.0(\mathrm{n}=47)$ & $\mathrm{p}=0.11^{3}$ \\
\hline Caucasian, \% & $92.3(\mathrm{n}=12)$ & $69.2(\mathrm{n}=9)$ & $84.7(\mathrm{n}=83)$ & $\mathrm{p}=0.33^{3}$ \\
\hline $\operatorname{LOS}^{1}$, days & $15.7(10.1 ; 12)$ & $16.3(10.3 ; 15)$ & $11.7(3.6 ; 12)$ & $\begin{array}{l}F=2.40 ; \text { d.f. }=2,121 \\
p=0.10\end{array}$ \\
\hline $\begin{array}{l}\text { Days between CVA and admission to } \\
\text { rehabilitation facility }\end{array}$ & $5.69(5.8 ; 4)$ & $9.2(12.9 ; 4)$ & - & $\begin{array}{l}F=0.05 ; \text { d.f. }=1,38 \\
p=0.83\end{array}$ \\
\hline Days between admission to rehabilitation & & & & $\mathrm{F}=0.53 ;$ d.f. $=1,38$ \\
\hline facility and start of medication ${ }^{1}$ & $2.6(1.5 ; 2)$ & $2.2(1.2 ; 2)$ & - & $\mathrm{p}=0.47$ \\
\hline Prestroke FIM-motor score ${ }^{4}$ & $90.2(2.8 ; 91)$ & $89.2(5.5 ; 91)$ & - & -5 \\
\hline Admission FIM-motor score & $49.4(8.34 ; 50)$ & $47.1(9.7 ; 47)$ & $49.7(14.7 ; 51)$ & $\begin{array}{l}F=0.21 ; \text { d.f. }=2,121 \\
p=0.81\end{array}$ \\
\hline Stroke location, $\mathrm{n}$ & & & - & $\mathrm{p}=0.204$ \\
\hline Brainstem & 3 & 0 & & \\
\hline Subcortical only & 4 & 7 & & \\
\hline Cortical only & 5 & 5 & & \\
\hline Cortical/subcortical & 1 & 2 & & \\
\hline AES & $35.5(10.3)$ & $39.9(11.8)$ & - & \\
\hline EXIT & $14.7(3.6)$ & $17.1(5.6)$ & - & \\
\hline HVLT (trial 4) & $4.5(2.5)$ & $4.6(3.2)$ & - & \\
\hline Digit span (summary score) & $14.2(3.3)$ & $11.7(4.0)$ & - & \\
\hline
\end{tabular}

Unless otherwise stated, data are means with standard deviations and medians in parentheses. AES = Apathy Evaluation Scale; $\mathrm{CVA}=$ cerebrovascular accident; EXIT = Executive Interview; HVLT = Hopkins Verbal Learning Test; LOS = length of stay for inpatient rehabilitation.

${ }^{1}$ Natural $\log$ transformation used in the analyses. ${ }^{2}$ Natural $\log (\mathrm{X}+0.1)$ transformation used in the analyses. ${ }^{3}$ Fisher's exact test. ${ }^{4}$ Reflects the participants' disability level prior to the index stroke as estimated by a structured interview with participants and their families. ${ }^{5}$ Statistical comparison not done as 26 participants had maximum possible prestroke FIM-motor score.

dropouts were older, more likely to be female and more disabled but did not differ on race, prestroke functional ability, length of rehabilitation hospitalization, or days between stroke and rehabilitation admission compared to the study completers (data not shown). Reasons for dropping out included: gastrointestinal side effects ( $\mathrm{n}=$ $5)$; concurrent medical problems $(\mathrm{n}=3)$; new onset agitation $(\mathrm{n}=1)$; withdrawal of consent $(\mathrm{n}=4)$, and subject relocation $(\mathrm{n}=1)$.

\section{Study Completers and Historical Comparator Group}

Study completers and the historical comparator group did not differ on baseline demographic and clinical characteristics (table 1). Only 9 of 13 galantamine study completers achieved the target dose $(24 \mathrm{mg} /$ day $)$, because of tolerability issues, whereas all 13 donepezil study completers achieved the target dose (10 mg/day). Side effect checklist scores did not differ between the 2 groups over time (data not shown).

\section{Functional Outcomes}

FIM-motor scores improved over time in all groups (fig. 1). However, by week 12, the donepezil group had experienced a greater improvement in FIM-motor scores than the galantamine group (final mean \pm SD: $87.4 \pm$ 5.2 vs. $73.1 \pm 16.5$ ); repeated measures ANOVA: group $\mathrm{F}=3.55$, d.f. $=1,19.8, \mathrm{p}=0.07$; time $\mathrm{F}=299.03$, d.f. $=2$, $22.8, \mathrm{p}<0.0001$; group $\times$ time $\mathrm{F}=7.41$, d.f. $=2,22.8$, $\mathrm{p}=0.003$. Furthermore, the galantamine group and the historical comparator group experienced a similar improvement while the donepezil group experienced a much greater improvement in the FIM-motor score than either of the other two groups; repeated measures ANOVA: group $\mathrm{F}=2.30$, d.f. $=2,26, \mathrm{p}=0.12$; time $\mathrm{F}=478.14$, 


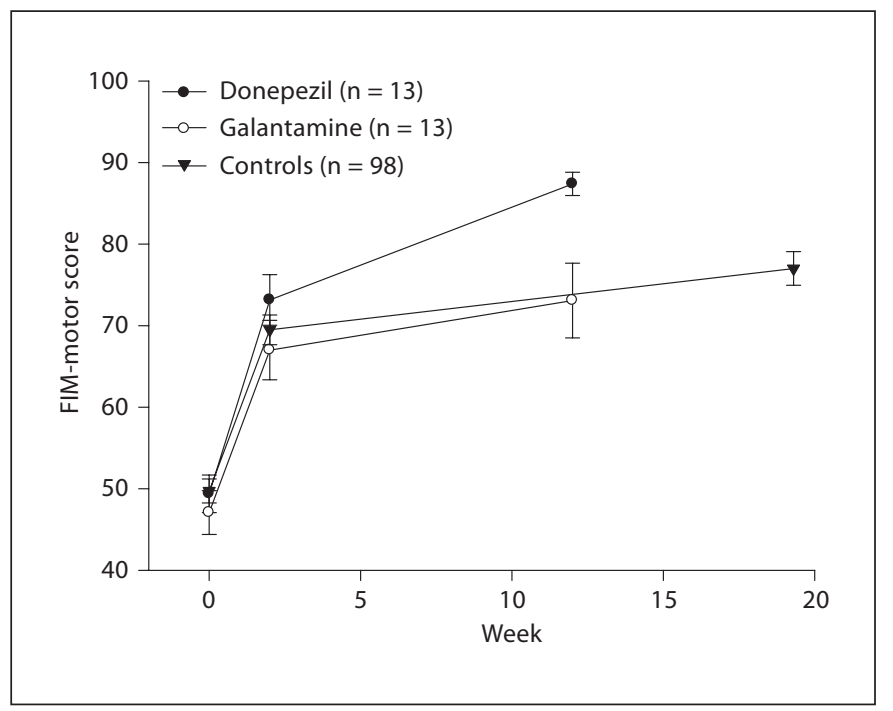

Fig. 1. Change in FIM-motor over time. The mean $( \pm$ standard error) time of each assessment is presented. Repeated measures ANOVA [unequal variance modeled with time as a class variable (baseline, 2 weeks and follow-up)]: drug $\mathrm{F}=2.30$, d.f. $=2,26, \mathrm{p}=$ 0.12 ; time $\mathrm{F}=478.14$, d.f. $=2,30.9, \mathrm{p}<0.0001$; drug $\times$ time $\mathrm{F}=$ 6.92 , d.f. $=4,28.6, \mathrm{p}=0.0005$. For the historical comparator (control) group, the time of final assessment was a mean of 19.3 weeks (standard deviation 2.8, median 19.4, range 13.1-26.1).

d.f. $=2,30.9, \mathrm{p}<0.0001$; drug $\times$ time $\mathrm{F}=6.92$, d.f. $=4$, 28.6, $\mathrm{p}=0.0005$.

\section{Cognitive Impairment and Apathy among Study Participants}

All cognitive tests improved significantly over time in the 2 AchEi groups without any significant group differences or group $\times$ time interactions. There was a trend towards a group difference in Executive Interview scores; repeated measures ANOVA: group $\mathrm{F}=3.98$, d.f. $=1,24$, $\mathrm{p}=0.06$; time $\mathrm{F}=13.20$, d.f. $=1,24, \mathrm{p}=0.001$; group $\times$ time $\mathrm{F}=1.53$, d.f. $=1,24, \mathrm{p}=0.23$. Change in the Executive Interview score, when added as a time-varying covariate to the repeated measures ANOVA model, was not associated with changes in the FIM-motor score. There was a trend supporting a change in apathy over time in the entire sample; repeated measures ANOVA: group $\mathrm{F}=$ 1.91 , d.f. $=1,24, \mathrm{p}=0.18$; time $\mathrm{F}=1.67$, d.f. $=2,24, \mathrm{p}=$ 0.21 ; group $\times$ time $\mathrm{F}=0.34$, d.f. $=2,24, \mathrm{p}=0.72$. The change in the Apathy Evaluation Scale score, when added as a time-varying covariate to the repeated measures ANOVA model, was associated with improvement in FIM-motor score over time; repeated measures ANOVA: apathy $\mathrm{F}=6.84$, d.f. $=1,23.9, \mathrm{p}=0.02 ; \operatorname{drug} \mathrm{F}=2.61$, d.f. $=1,19.4, \mathrm{p}=0.12$; time $\mathrm{F}=270.12$, d.f. $=2,22.1, \mathrm{p}<$ 0.0001 ; drug $\times$ time $\mathrm{F}=7.29$, d.f. $=2,21.5, \mathrm{p}=0.004$.

\section{Discussion}

To our knowledge this is the first study to examine AchEi for promoting functional recovery after stroke when combined with inpatient rehabilitation. Participants who received donepezil had a more successful rehabilitation outcome than either the galantamine participants or the historical comparator group - a notable finding given the small number of participants. As lower FIM scores correlate with greater need for caregiver assistance [20], the larger FIM improvement in the donepezil group may clinically translate into a need for less hands-on care.

While this early result is intriguing, there are several study limitations, including: (1) the lack of a concurrent placebo control group, (2) the small number of participants, and (3) the lack of randomization or blinding. However, drug assignment was unrelated to any participant characteristics, and the FIM rater was blind to drug assignment. Furthermore, the small number of galantamine subjects completing the study at the target dose of galantamine (relative to the number of donepezil subjects who achieved the target dose) limits our ability to compare the efficacy of these 2 drugs. However, this limitation does not undermine the real-world significance of our result that subjects randomized to donepezil tolerated the study medication and performed better on FIMmotor at week 12 compared to the historical comparator group. Notwithstanding these limitations, our finding provides preliminary support for the feasibility of using AchEi in post-stroke cognitively impaired elders undergoing inpatient rehabilitation. The study drugs were generally well tolerated, consistent with findings in vascular dementia [11-13].

AchEi may lead to improved rehabilitation outcomes through several possible pathways. First, AchEi may acutely enhance cognitive function, thereby increasing a patient's ability to learn during rehabilitation. Second, they may reduce apathy, thereby leading a patient to be a more 'motivated' participant in rehabilitation. Third, they may lead to greater activation of the motor cortex and perhaps enhance motor cortex reorganization after stroke [21]. The latter possibility is supported by a small randomized controlled trial in which participants with significant residual upper-limb paresis 1 year after stroke 
demonstrated a trend towards superior motor improvement when constraint-induced therapy was combined with donepezil [22].

The observed difference in functional improvement between donepezil and galantamine participants may reflect the drugs' different pharmacokinetic profiles. In placebo-controlled trials for Alzheimer's disease, donepezil [23] but not galantamine [24] demonstrated efficacy at the starting dose, suggesting that donepezil can penetrate the blood-brain barrier at lower doses.

In summary, this pilot study suggests that donepezil is safe and fairly well tolerated by cognitively impaired elderly stroke patients and, when combined with inpatient rehabilitation, may lead to improved functional outcomes. A randomized trial by our group is underway to establish donepezil's efficacy in promoting functional recovery in the immediate post-stroke period and to clarify the mechanism by which it leads to improved functional recovery.

\section{Acknowledgments}

This study was supported by investigator-initiated grants from Janssen and Pfizer Pharmaceuticals, as well as by PHS MH067710, MH064196, and P30 MH071944 (ACISR/LLMD).

\section{References}

1 Ballard C, Stephens S, McLaren A, Wesnes K, Kenny R: Mild cognitive impairment and vascular cognitive impairment in stroke patients. Int Psychogeriatr 2003;15(suppl 1):123-126.

-2 Starkstein SE, Fedoroff JP, Price TR, Leiguarda R, Robinson RG: Apathy following cerebrovascular lesions. Stroke 1993;24: 1625-1630.

-3 Ozdemir F, Birtane M, Tabatabaei R, Ekuklu G, Kokino S: Cognitive evaluation and functional outcome after stroke. Am J Phys Med Rehabil 2001;80:410-415.

-4 Heruti RJ, Lusky A, Dankner R, Ring H, Dolgopiat M, Barrell V, Levenkrohn S, Adunsky A: Rehabilitation outcome of elderly patients after a first stroke: effect of cognitive status at admission on the functional outcome. Arch Phys Med Rehabil 2002;83:742-749.

5 Resnick B, Zimmerman SI, Magaziner J, Adelman A: Use of the apathy evaluation scale as a measure of motivation in elderly people. Rehabil Nurs 1998;23:141-147.

6 Black S, Román GC, Geldmacher DS, Salloway S, Hecker J, Burns A, Perdomo CA, Kumar D, Pratt RD: Efficacy and tolerability of donepezil in vascular dementia: positive results of a 24-week, multicenter, international, randomized, placebo-controlled clinical trial. Stroke 2003;34:2323-2332.

-7 Wilkinson D, Doody R, Helme R, Taubman K, Mintzer J, Kertesz A, Pratt RD: Donepezil in vascular dementia. A randomized, placebo-controlled study. Neurology 2003;61: 479-486.
8 Erkinjuntti T, Kurz A, Gauthier S, Bullock R, Lilienfeld S, Damaraju CV: Efficacy of galantamine in probable vascular dementia and Alzheimer's disease combined with cerebrovascular disease: a randomised trial. Lancet 2002;359:1283-1290.

9 Moretti R, Torre P, Antonello RM, Cattaruzza T, Cazzato G: Cholinesterase inhibitors as a possible therapy for delirium in vascular dementia: a controlled, open 24-month study of 246 patients. Am J Alzheimers Dis Other Demen 2004;19:333-339.

10 Almkvist O, Jelic V, Amberla K, HellstromLindahl E, Meurling L, Nordberg A: Responder characteristics to a single oral dose of cholinesterase inhibitor: a double-blind placebo-controlled study with tacrine in Alzheimer patients. Dement Geriatr Cogn Disord 2001;12:22-32.

11 Kaufer DI: Cholinergic therapy for neuropsychiatric symptoms in neurologic disorders. Curr Psychiatry Rep 1999;1:78-84.

12 Cummings JL, Kaufer D: Neuropsychiatric aspects of Alzheimer's disease: the cholinergic hypothesis revisited. Neurology 1996;47: 876-883.

13 Shapiro AM, Benedict RH, Schretlen D, Brandt J: Construct and concurrent validity of the Hopkins Verbal Learning Test - revised. Clin Neuropsychol 1999;13:348-358.

14 Wechsler D: Wechsler Adult Intelligence Scale - III. San Antonio, The Psychological Corporation, 1996.

15 Royall DR, Mahurin RK, Gray KF: Bedside assessment of executive cognitive impairment: the Executive Interview. J Am Geriatr Soc 1992;40:1221-1226.

16 Guide for the Uniform Data Set for Medical Rehabilitation (Adult FIM). Buffalo, State University of New York at Buffalo, 1993.
17 Marin RS, Biedrzycki RC, Firinciogullari S Reliability and validity of the Apathy Evaluation Scale. Psychiatry Res 1991;38:143162

18 Linacre JM, Heinemann AW, Wright BD The structure and stability of the Functional Independence Measure. Arch Phys Med Rehabil 1994;75:127-132.

19 Brown H, Prescott R: Applied Mixed Models in Medicine. Chichester, Wiley \& Sons, 1999.

-20 Granger CV, Cotter AC, Hamilton BB, Fiedler RC: Functional assessment scales: a study of persons after stroke. Arch Phys Med Rehabil 1993;74:133-138.

21 Berthier ML, Pujol J, Gironell A, Kulisevsky J, Deus J, Hinojosa J, Soriano-Mas C: Beneficial effect of donepezil on sensorimotor function after stroke. Am J Phys Med Rehabil 2003;82:725-729.

22 Nadeau SE, Behrman AL, Davis SE, Reid K, Wu SS, Stidham BS, Helms KM, Gonzalez Rothi LJ: Donepezil as an adjuvant to constraint-induced therapy for upper-limb dysfunction after stroke: an exploratory randomized clinical trial. J Rehabil Res Dev 2004;41:525-534.

23 Rogers SL, Farlow MR, Doody RS, Mohs R, Friedhoff LT: A 24-week, double-blind, placebo-controlled trial of donepezil in patients with Alzheimer's disease. Donepezil Study Group. Neurology 1998;50:136-145.

24 Raskind MA, Peskind ER, Wessel T, Yuan W: Galantamine in AD: a 6-month randomized, placebo-controlled trial with a 6-month extension. The Galantamine USA-1 Study Group. Neurology 2000;54:2261-2268. 